\title{
Uzun ve Kısa Süreli Periyotlarda Kuraklık Analizi: Bursa Örneği
}

\author{
Ülker Güner Bacanlı1,*, Pınar Gökçe Karg1 1,** \\ ${ }^{1}$ Pamukkale Üniversitesi, Mühendislik Fakültesi, Inşaat Mühendisliği Bölümü, 20070, Denizli. \\ "ORCID: 0000-0002-2279-9138, "* ORCID: 0000-0002-8089-9030
}

\section{Özet}

Insan yașamında doğal afetler önemli yer alır. Kuraklık, iklimsel ve bölgesel özelliklere bağlı olan ve tüm canlı yaşamını olumsuz etkileyen bir afettir. Kuraklığın belirlenmesi ve gerekli tedbirlerin alınabilmesi için bölgenin ayrıntılı analizi gerekmektedir. Araştırmacılar, kuraklı̆̆ı saptamak için farklı kuraklık indislerini kullanmışlardır. Standart Yă̆ış İndisi (SYI)), farklı zaman ölçeklerinde hesapların yapılabildiği ve literatürde en sık kullanılan kuraklık indislerinden biridir. Bu çalışmada, Bursa ilinde uzun süreli yağış verisi bulunan Bursa, İznik, Keleş, Mustafakemalpaşa ve Uludağ istasyonları 1969-2015 dönemi için incelenmiştir. Yağış verilerinin ĕgilimi olup olmadiğ lineer regresyon analiziyle belirlenmiştir. Yağış verileri standardize edilerek gidişler analizine göre değerlendirilmiştir. Son olarak da ülkemizde ve dünyada yaygın olarak kullanılan Standart Yağış İndisi (SYİ) yöntemi ile 1, 3, 6, 9, 12, 24 ve 48 aylık zaman periyotları için kuraklık analizi yapılmıştır. Yıllık ve aylık yağıș verilerinde önemli bir eğilim saptanmamıștır. Aralık ayında İznik, Keleş, Uludă̆ istasyonları azalma ĕgilimi; Ekim ayında Bursa istasyonu azalma eğilimi gösterdiği bulunmuştur. İstatistiksel olarak anlaml ĕ̌̆ilim (\%5 risk) diğer aylarda saptanmamıştır. Standart Yağıs̆ İndisi (SYİ) analizi sonuçlarında istasyonların kurak, normal veya sulak periyot oranları benzerlik göstermiştir. Bununla birlikte, kisa süreli periyotlarda (3-6 ay) normal veya hafif kurakliklara daha sık rastlanırken, uzun süreli periyotlarda (12-24-48 ay) şiddetli ve çok şiddetli kuraklık gözlenmiştir.

\section{Anahtar Sözcükler}

Kuraklık, Standart Yağıș İndisi, Gidișler Analizi, Bursa

\section{Drought Analysis in Long and Short Term Periods: Bursa Case}

\begin{abstract}
Natural disasters are important in human life. Drought is a disaster that depends on climatic and regional characteristics and affects all lives negatively. A detailed analysis of the region is necessary to determine the drought and take necessary measures. The researchers used different drought indices to determine drought. Standardized Precipitation Index (SPI) is one of the most commonly used drought indices that accounts different time scales. In this study, Bursa, Iznik, Keles, Mustafakemalpaşa, Uludag stations with long-term precipitation data in Bursa were examined for 1969-2015. The trend of precipitation data was determined by linear regression analysis. Precipitation data were standardized and evaluated according to the runs analysis. Lastly, drought analysis was performed for the periods 1, 3, 6, 9, 12, 24 and 48 months by the Standard Precipitation Index (SYI) method, which is widely used in our country and in the world. There was no significant trend in annual and monthly rainfall data. It was found that the monthly precipitation showed downward trend at Iznik, Keles, Uludag stations in December and at Bursa station in October. A statistically significant trend (5\% risk) was not found in other months. Results of Standardized Precipitation Index are showed similarity which drought, normal and wet period rations in all stations. However, while normal or mild droughts are more frequent in short term periods (3-6 months), severe or very severe droughts have been observed over long term periods (12-24-48 months).
\end{abstract}

$\underline{\text { Keywords }}$

Drought, Standard Precipitation Index, Runs Analysis, Bursa

\section{Giriş}

Kuraklık doğal afetlerden biridir. Herhangi bir mevsim veya bir zaman diliminde, yerel bir bölgede önemli ölçüde yağış azalması ya da dengesizliğinden dolayı başlar. Yüksek sıcaklık, yüksek rüzgâr hızı, düşük nem gibi diğer iklim faktörlerinin etkisi ile yoğunlaşır (Sırdaș ve Şen; 2003, Chen vd. 2009, Fontaine ve Steinemann 2009). Kuraklık şiddeti ve yoğunluğunun artmasıyla; iklim koşulları ve bitki örtüsünün bozulmasından canlı yaşamının bitmesine kadar varan etkiler oluşabilir (Kallis 2008). Kuraklık, tüm ekosistemi, tarımı, çevreyi, ekonomiyi kısaca tüm yaşamı olumsuz etkilemektedir. Kuraklığın önlenmesi ve gerekli tedbirlerin alınabilmesi için bölgenin detaylı analizi ve izlenmesi gereklidir. Araştırmacılar, geçmişten günümüze pek çok parametrelerle kuraklığı incelemişlerdir. Farklı kuraklık indislerini (örn Palmer Kuraklık Şiddet İndeksi, Erinç, Standart Yağış İndeksi veya De Martonne, Thornthwaite yöntemleri) kuraklığı belirlemek için kullanmışlardır. 
Ayrıca kuraklık analizinde entropi, trend analizi ve istatistik / stokastik değerlendirmeler de kullanılmıştır (Bacanlı vd. 2011; Bacanlı vd. 2017; Baran vd. 2017; Bacanlı 2017). Kuraklık için doğru bir indis geliştirmek, iklim değişkenleri ile kuraklık arasındaki ilişkilerin karmaşıklığına bağlı olarak zordur. Kuraklığın analizi için su bütçesi hesaplamalarına dayalı indisler önerilmiştir. Önerilen indisler, meteorolojik, hidrolojik veya tarımsal kuraklığı dikkate alır.

Standart Yağış İndisi (SYİ), en sık kullanılan kuraklık indislerindendir. Farklı zaman ölçeklerinde hesaplar yapılabilmektedir (Mckee vd. 1993; Mckee vd. 1999). SYİ'nin nispeten basit bir algoritması vardır (Keyantash ve Dracup 2002; Wu vd. 2001; Wu vd. 2005; Vicente-Seriano vd. 2004; Cancelliere vd. 2007; Raziei vd. 2009; Liu vd. 2012a; Zhang vd. 2012; Mallya vd. 2016).

Standart Yağış İndisi (SYİ) ile farklı ülkelerde pek çok çalışma yapılmıştır. Bunlardan bazı çalışmalar şunlardır. Topçu ve Seçkin (2013), 11 istasyonda SYİ yöntemiyle Seyhan Havzası'nın kuraklık durumu incelenmiştir. SYİ yöntemiyle belirlenen en kurak ayların yağış değerlerine L-momentler yöntemiyle bölgesel frekans analizi uygulanmıştır. Gocic ve Trajkovic (2014), Sırbistan'da 1948-2012 dönemleri için kuraklık analizi yapmışlardır. Zarch vd. (2015), SYİ ve yağışın yanında Potansiyel Evapotranspirasyon (PET) verileri dikkate alınarak hesaplanan Keşif Kuraklık İndisi (RDI) kullanılarak kuraklık analizi yapmışlardır. Guhathakurta vd. (2017), Hindistan’1 5 alt bölgeye ayırarak 1901-2015 yılları arasında kuraklık analizi yapmıştır. Labedzki (2017), Polonya’da SYİ kullanarak yağış koşullarını değerlendirmiştir.

Bu çalışmada, Bursa ilindeki seçilmiş istasyonların verileri 1969-2015 döneminde, meteorolojik kuraklığı tanımlamak için değerlendirilmiştir. Öncelikle istasyonlara ait aylık ve yıllık yağış değerleri incelenmiştir. Standardize edilmiş yağış verileri ile farklı kesme seviyelerinde kuraklık süresi (L) ve genliği (M) belirlenmiştir. Ayrıca Standart Yağış İndisi (SYİ) yöntemi ile 1, 3, 6, 9, 12, 24 ve 48 aylık zaman dilimlerinde kuraklık analizi yapılmıştır.

\section{Veri}

Yüzölçümü 10.819 km² olan Bursa, Marmara Bölgesi’nde yer almakla beraber Türkiye'nin 4. büyük ilidir. Bursa ili Akdeniz iklimi ile Karadeniz iklimi arasında bir geçiş iklimi tipine sahiptir. Ancak, iklim bölgelere göre de değişiklik göstermektedir. Kuzeyde Marmara Denizinin yumuşak ve 1lık iklimine karşın güneyde Uludağ’ın sert iklimi ile karşılaşılmaktadır. Bursa'da en yüksek sıcaklık Temmuz ayında gözlenirken en düşük sıcaklıkla Şubat ayında karşılaşılmaktadır. Yıllık yağışlar ortalaması 707,5 mm (MGM 2018) olan Bursa ili en fazla yağışı Aralık ayında almaktadır. Bu çalışmada kullanılan Bursa ilinde DMİ (Devlet Meteoroloji İşleri)'ye ait meteoroloji gözlem istasyonları Şekil 1'de, istasyon özellikleri ise Tablo 1'de verilmiştir. 1969 - 2015 ölçüm periyodunda seçilmiş istasyonlarda gözlenen maksimum yağış, 747,6 mm ortalama yağış ise $50,94 \mathrm{~mm}$ dir.

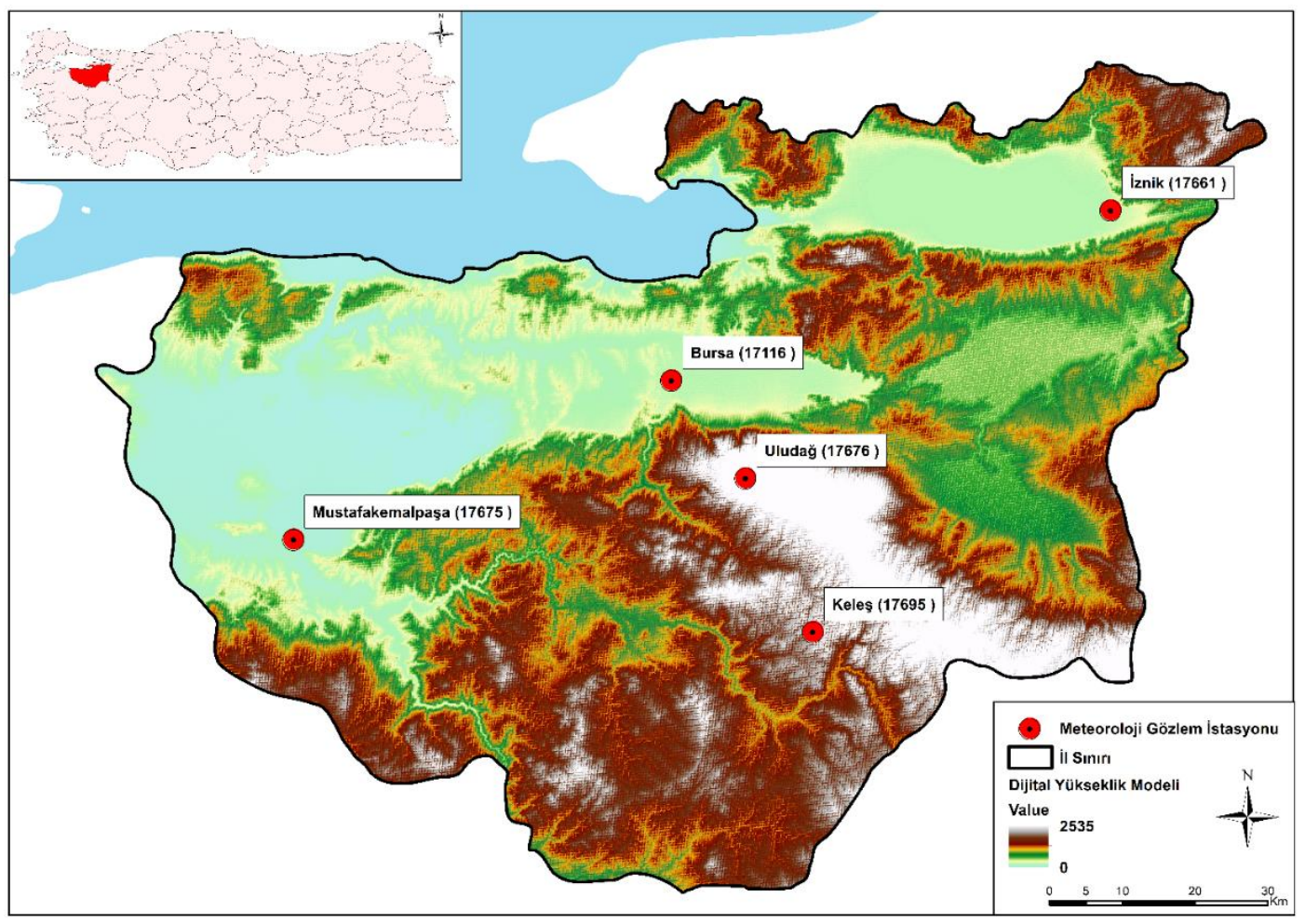

Şekil 1: Bursa Ili Meteoroloji Gözlem Istasyonları 
Tablo 1: İstasyonlarının Özellikleri

\begin{tabular}{ccccc}
\hline İstasyon No & İstasyon Adı & Enlem (K) & Boylam (D) & Yükseklik (m) \\
\hline $\mathbf{1 7 1 1 6}$ & Bursa & 40,23 & 29,01 & 100 \\
\hline $\mathbf{1 7 6 6 1}$ & İznik & 40,43 & 29,73 & 90 \\
\hline $\mathbf{1 7 6 9 5}$ & Keleş & 39,92 & 29,23 & 1063 \\
\hline $\mathbf{1 7 6 7 5}$ & Mustafakemalpaşa & 40,04 & 28,40 & 60 \\
\hline $\mathbf{1 7 6 7 6}$ & Uludă & 40,11 & 29,13 & 1877 \\
\hline
\end{tabular}

\section{Yöntem}

\subsection{Regresyon Analizi}

Bir rastgele değişkenin değerini bir veya daha fazla sayıda rastgele değişkenlerin değerlerine bağlı olarak en iyi şekilde tahmin etmeye yarayan regresyon denkleminin belirlenmesine de regresyon analizi denir. Lineer regresyonda, $y=a+b x$ şeklindeki regresyon denkleminde, b sabiti değişimin yönünü ve miktarını vermektedir. b'nın pozitif olması artan bir değişimi, negatif olması azalan bir değişimi ifade eder. b’nın sıfırdan çok farklı olmaması ise bir değişimin olmadığını gösterir (Bayazit ve Yeğen Oğuz 2005).

\subsection{Standart Yağış İndisi}

McKee vd. (1993) tarafından geliştirilen Standart Yağış İndisi (SYİ) yöntemi, kuraklığı izlemek için yaygın olarak kullanılan yöntemlerden biridir. Farklı süreli periyotlarda izleme olasılığı verir ve boyutsuz bir kuraklık indisidir. Yağış veri serisi öncelikle uygun bir olasılık dağılımı içine uygulanır. Olasılık yoğunluk fonksiyonu belirlendikten sonra, gözlenen bir yağış miktarının kümülatif olasılığı hesaplanır. Daha sonra, Gauss fonksiyonu, kümülatif olasılığa uygulanır. Buradan SYİ hesaplanır (Guttman 1998; Guttman 1999).

SYİ normalleştirilmiş olasılık dağılımı yardımıyla hem kuru hem de nemli bölgelerde rahatlıkla uygulanabilir. SYİnin değeri, belirli bir olasılık dağılım fonksiyonunun ölçülen yağışın standart sapmasını ifade eder. Varsayılan x araştırma zaman ölçeği (1 ay, 3 ay, 6 ay, 12 ay, vs.) kümülatif aylık yağıştır. Thom (1958), Gama olasılık dağılımının klimatolojik zaman serilerine en uygun dağılım olduğunu ortaya koymuştur. Gama dağılım, olasılık yoğunluk fonksiyonu $\mathrm{g}(\mathrm{x})$ ile tanımlanmaktadır.

$$
\begin{array}{ll}
g(x)=\frac{1}{\beta^{\alpha} C(\alpha)} x^{\alpha-1} e^{-x / \beta} & x>0 \\
C(x)=\int_{0}^{\infty} x^{\alpha-1} e^{-x} d x &
\end{array}
$$

Burada $x$ yağış toplamı, $C(x)$ Gama işlevidir. Denklem 1 ve 2'de, sırasıyla $\alpha$ ve $\beta$ şekil ve ölçek parametrelerini temsil eder. Bu parametreler maksimum olasılık yöntemi ile tahmin edilir (Guttman 1999; Yuan ve Zhou 2008; Liu vd. 2012b).

$$
\begin{array}{ll}
\alpha=\frac{1+\sqrt{1+4 A / 3}}{4 A} & \quad \beta=\frac{\bar{x}}{\alpha} \\
A & =\ln (\bar{x})-\frac{\ln \sum(x)}{n}
\end{array}
$$

Burada $n$ (ay) zaman serilerinin uzunluğudur. Sonra belirli bir zaman ölçeğindeki $x$ yağış kümülatif olasılık olarak aşağıdaki gibi tanımlanır.

$$
G(x)=\int_{0}^{x} g(x) d x=\frac{1}{\beta^{\alpha} C(x)} \int_{0}^{x} x^{\alpha-1} e^{-x / \beta} d x
$$

$$
t=x / \beta \text { ise ve denklem (5) aşağıdaki Gamma fonksiyonuna dönüşür. }
$$




$$
G(x)=\frac{1}{C(\alpha)} \int_{0}^{x} t^{\alpha-1} e^{-t} d t
$$

Denklem (6)'da kümülatif aylık yağış $x=0$ olduğu zaman aşırı durum göz önüne alınmaz. Sonuçta, denklem $H(x)$ olarak yeniden düzenlenir.

$$
H(x)=q+(1-q) G(x)
$$

Burada, $q, x=0$ 'ın olasılığgdır yani tüm gözlem serilerinde $x=0$ oluşma sıklığıdır. Standardize normal dağılım fonksiyonuna dönüştürüldüğü zaman, SYİ aşağıdaki gibi ifade edilir.

$$
S Y \dot{I}=\left\{\begin{array}{cc}
-\left(t-\frac{c_{0}+c_{1}+c_{2} t^{2}}{1+d_{1} t+d_{2} t^{2}+d_{3}} t^{3}\right) & , \quad t=\sqrt{\ln \left(\frac{1}{H(x)^{2}}\right)}, 0<H(x) \leq 0,5 \\
t-\frac{c_{0}+c_{1}+c_{2} t^{2}}{1+d_{1} t+d_{2} t^{2}+d_{3}} t^{3} & , \quad t=\sqrt{\ln \left(\frac{1}{1-H(x)^{2}}\right)}, 0<H(x) \leq 0,5
\end{array}\right.
$$

Burada sabitler $c_{0}=2,515517, \quad c_{1}=0,802853, \quad c_{2}=0,010328, \quad d_{1}=1,432788, \quad d_{2}=0,189269, \quad d_{3}=$ 0,001308 şeklinde ifade edilir.

SYİ yöntemine göre yapılan sınıflandırma Tablo 2'de verilmiştir. Eğer SYİ negatif ise kurak ve yağışın eksik olduğu dönemleri; SYİ pozitif ise kuraklığın olmadığı ve yağışın olduğu dönemleri belirttiği değerlendirilir (Mishra ve Singh 2011).

Tablo 2: Standart Yağış Indisi Sınıflandırması (Mckee vd. 1999)

\begin{tabular}{cc}
\hline SYI Değerleri & Kuraklık Kategorisi \\
\hline$\geq 2$ & Aşırı Sulak (W3) \\
\hline $1,50 \sim 1,99$ & Sulak (W2) \\
\hline $1,00 \sim 1,49$ & Hafif Sulak (W1) \\
\hline $0,99 \sim-0,99$ & Normal (N) \\
\hline$-1,00 \sim-1,49$ & Hafif Kurak (D1) \\
\hline$-1,50 \sim-1,99$ & Kurak (D2) \\
\hline$\leq-2$ & Aşırı Kurak (D3) \\
\hline
\end{tabular}

\subsection{Gidişler Analizi}

Kuraklık incelenmesinde, yağış zaman serisi standardize edilir. Veriler ortalamadan çıkarılıp, standart sapmasına bölünür. Standardize edilmiş verilerde Şekil 2'de de görüldüğü gibi kurak dönemler $L_{1}, L_{2}, \ldots, L_{m}$ 'dir. $X_{o}$ kesme seviyesinde " $m$ " kurak periyot sayısıdır. $X_{o}$ kesme seviyesinde kurak periyodun altındaki eksikliklerin toplamı genlik $\left(M_{1}, M_{2}, \ldots, M_{m}\right)$ dir. Genlik,

$$
M_{j}=\sum_{i=1}^{m}\left|X_{o}-x_{i}\right|
$$

ile elde edilir. Kuraklık şiddeti ise genliğin süreye oranı şekilde hesaplanır (Sırdaş ve Şen 2003):

$$
I_{j}=\frac{M_{j}}{L_{j}}
$$




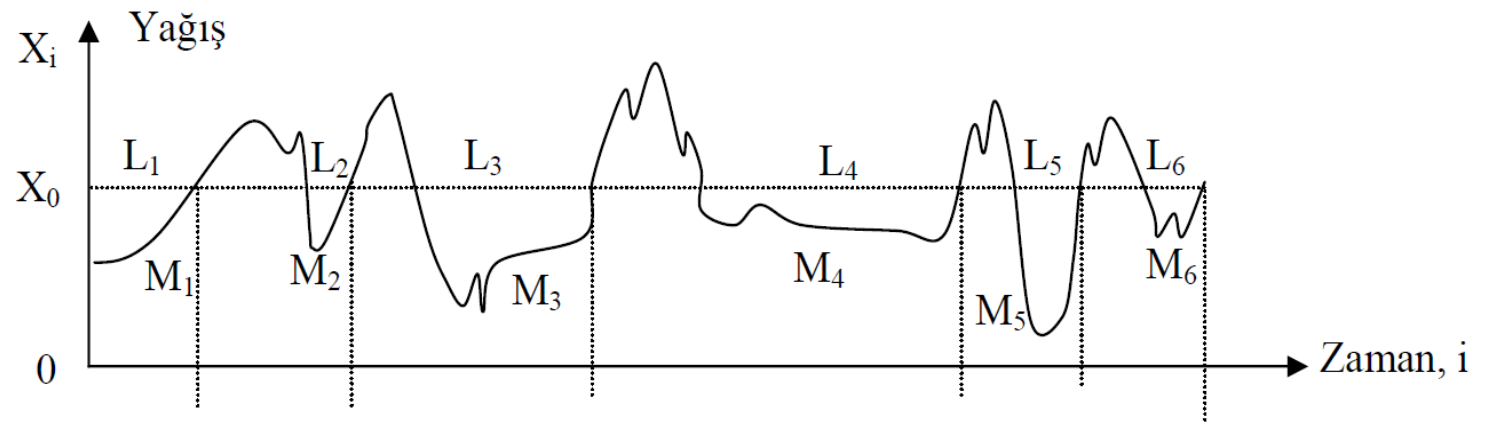

Şekil 2: Kurak ve sulak gidişler ( $M_{i}:$ kurak genlik; $L_{i}$ : kurak süre)

\section{Bulgular}

\subsection{Yağış Analizi}

Sunulan çalışmada Bursa bölgesinde kesintisiz uzun verisi bulunan Bursa, İznik, Keleş, Mustafakemalpaşa ve Uludağ istasyonlarına ait aylık ve yıllık yağış değerleri 1969-2015 periyodunda incelenmiştir. Lineer regresyon analizi yapılmıştır. Şekil 3'de İznik istasyonu yağış verileri gidişi görülmektedir.

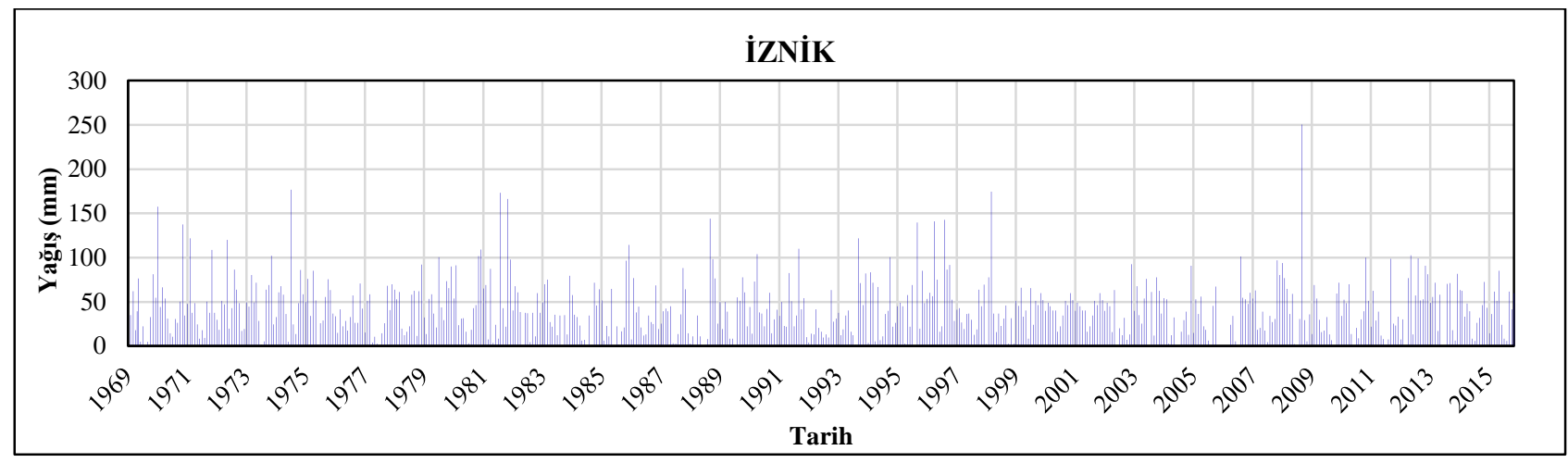

Şekil 3: Iznik istasyonu yağış verileri

Yıllık yağış verilerinde önemli bir eğilim saptanmamıştır. Aylık yağış verilerinin lineer regresyon analizi yapılmıştır. Tablo 3'de her ay için 1969-2015 yıllarındaki korelasyon katsayısı verilmiştir. Genel olarak yağış verilerinde azalma eğilimi görülmektedir. Ancak istatistiksel olarak \%95 güven (\%5 risk) düzeyinde, t testine göre; Aralık ayında İznik, Keleş ve Uludağ istasyonlarında azalma eğilimi; Ekim ayında Bursa istasyonunda azalma eğilimi saptanmıştır.

Tablo 3: Aylık Yağış değerlerinin korelasyon katsayısı sonuçları

\begin{tabular}{cccccc}
\hline AYLAR & BURSA & IZNIK & KELEŞ & M.KEMALPAŞA & ULUDAĞ \\
\hline 1 & 0,00 & 0,04 & $-0,17$ & $-0,20$ & $-0,02$ \\
\hline 2 & 0,10 & $-0,26$ & $-0,22$ & 0,08 & $-0,10$ \\
\hline 3 & 0,15 & 0,01 & 0,02 & $-0,02$ & $-0,07$ \\
\hline 4 & $-0,01$ & $-0,13$ & $-0,21$ & 0,03 & $-0,17$ \\
\hline 5 & $-0,21$ & $-0,04$ & $-0,22$ & $-0,21$ & $-0,26$ \\
\hline 6 & 0,19 & 0,08 & $-0,09$ & 0,10 & $-0,14$ \\
\hline 7 & $-0,15$ & $-0,01$ & 0,01 & $-0,26$ & $-0,18$ \\
\hline 8 & $-0,21$ & $-0,23$ & $-0,06$ & $-0,22$ & $-0,12$ \\
\hline 9 & 0,26 & 0,01 & 0,24 & 0,21 & 0,30 \\
\hline 10 & $\mathbf{- 0 , 3 1}$ & 0,22 & 0,27 & 0,11 & 0,12 \\
\hline 11 & $-0,15$ & $-0,14$ & $-0,23$ & $-0,13$ & $-0,13$ \\
\hline 12 & $-0,24$ & $\mathbf{- 0 , 3 6}$ & $\mathbf{- 0 , 3 3}$ & $-0,17$ & $\mathbf{- 0 , 3 9}$
\end{tabular}




\subsection{Gidiş Analizi}

Sunulan çalışmada yağış verileri standardize edilmiștir. Farklı kesme seviyelerinde kuraklık süresi (L) ve genliği (M) arasındaki $\mathrm{M}=\mathrm{a}+\mathrm{bL}$ şeklinde doğrusal bağıntılar Tablo 4'de verilmiştir. Kesme seviyesinin artmasıyla $\mathrm{M}$ ve $\mathrm{L}$ arasındaki korelasyon katsayısı (r) değeri artış göstermiştir. Kesme seviyesinin artmasıyla maksimum toplam su eksikliği artmıştır.

Tablo 4: Farklı kesme seviyelerinde kuraklık süresi (L) ve genliği $(M)$ arasındaki $M=a+b L$ doğrusal bağıntının a ve $b$ katsayıları ve korelasyon katsayısı sonuçları

\begin{tabular}{|c|c|c|c|c|c|c|c|c|c|c|c|c|c|c|c|}
\hline & \multicolumn{3}{|c|}{ BURSA } & \multicolumn{3}{|c|}{ İZNIKK } & \multicolumn{3}{|c|}{ KELEŞ } & \multicolumn{3}{|c|}{ M.KEMALPAŞA } & \multicolumn{3}{|c|}{ ULUDAĞ } \\
\hline KS & $\mathbf{a}$ & b & $\mathbf{r}$ & $\mathbf{a}$ & b & $\mathbf{r}$ & $\mathbf{a}$ & b & $\mathbf{r}$ & $\mathbf{a}$ & $\mathbf{b}$ & $\mathbf{r}$ & $\mathbf{a}$ & b & $\mathbf{r}$ \\
\hline-1 & $-0,001$ & 0,06 & 0,64 & $-0,07$ & 0,23 & 0,82 & $-0,05$ & 0,16 & 0,79 & $-0,03$ & 0,14 & 0,75 & $-0,03$ & 0,14 & 0,67 \\
\hline-0.5 & $-0,05$ & 0,34 & 0,87 & $-0,18$ & 0,53 & 0,88 & $-0,19$ & 0,49 & 0,91 & $-0,06$ & 0,43 & 0,90 & $-0,20$ & 0,48 & 0,93 \\
\hline 0 & $-0,17$ & 0,67 & 0,94 & $-0,26$ & 0,76 & 0,91 & $-0,27$ & 0,76 & 0,92 & $-0,28$ & 0,77 & 0,94 & $-0,24$ & 0,76 & 0,95 \\
\hline 0.5 & $-0,28$ & 0,97 & 0,97 & $-0,19$ & 1,00 & 0,91 & $-0,40$ & 1,09 & 0,96 & $-0,42$ & 1,07 & 0,95 & $-0,24$ & 1,05 & 0,97 \\
\hline 1 & 0,11 & 1,23 & 0,98 & 0,30 & 1,24 & 0,98 & $-0,28$ & 1,40 & 0,97 & 0,02 & 1,33 & 0,97 & $-0,20$ & 1,36 & 0,97 \\
\hline
\end{tabular}

\subsection{Standart Yağış İndisi (SYI) Analizi}

Çalışmada, yaygın olarak kullanılan Standart Yağış İndisi (SYI) yöntemi uygulanmıştır. 1, 3, 6, 9, 12, 24 ve 48 aylık zaman periyotları için SYİ hesaplanmıştır. Belirtilen zaman periyotları için hesaplanan SYİ değerleri her istasyon için Şekil 4'te verilmiştir. Şekil 5'te ise yine aynı zaman periyotları için frekans analizi yapılmış ve grafik olarak verilmiştir. İstasyonlarda farklı zaman aralıklarında hesaplanan SYİ sınıflamaları değerlendirildiğinde, istasyonların kurak ve sulak periyotlarının oranlarına göre anlamlı bir değişim görülmemiştir. Ancak, 1, 3, 6 aylık periyotlarda normal veya hafif kuraklıklara daha sık rastlanırken, 12, 24 ve 48 aylık periyotlarda şiddetli ve çok şiddetli kuraklık gözlenmiştir.
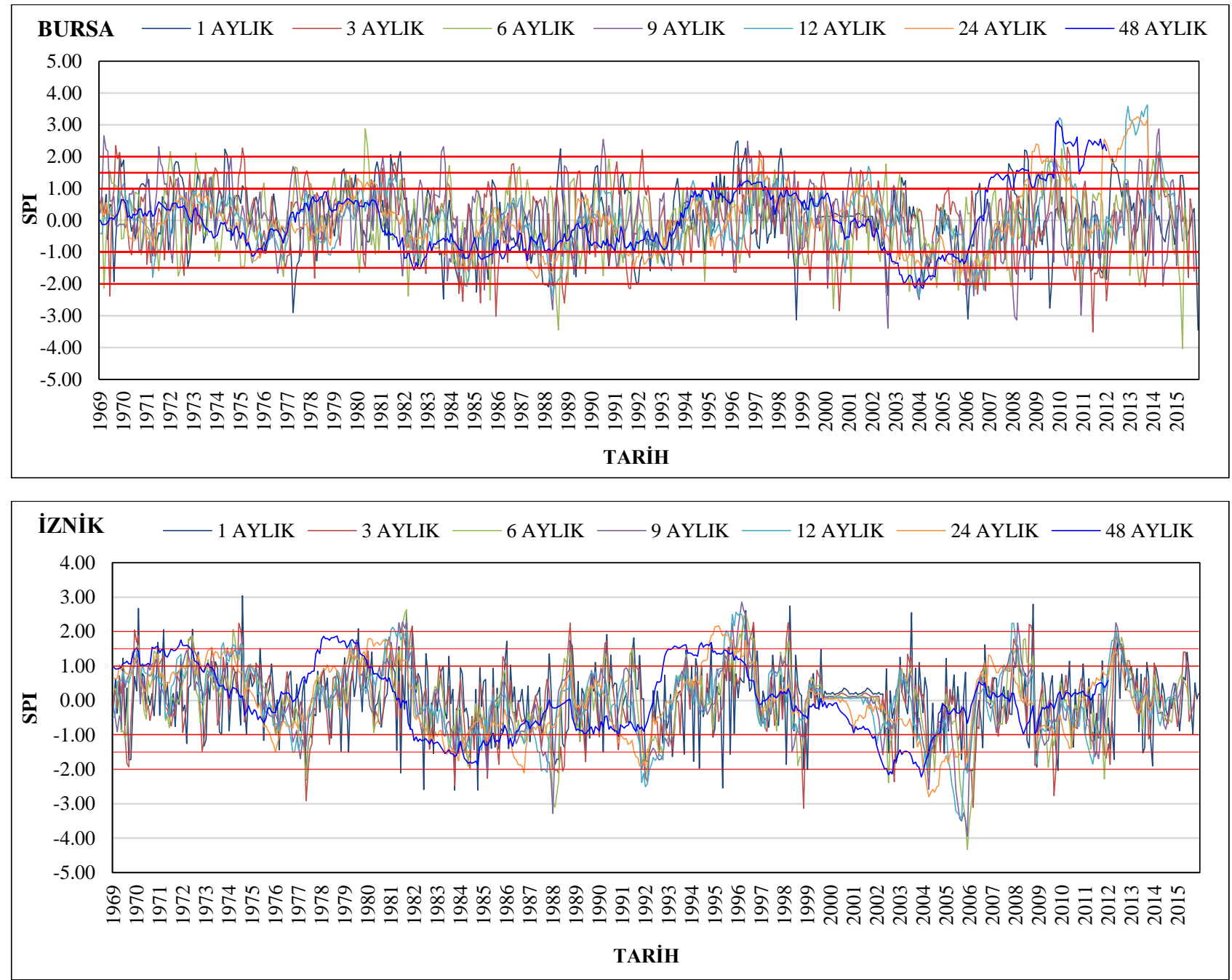

Şekil 4: Istasyonların 1, 3, 6, 9, 12, 24 ve 48 aylık SYI değerleri 
İstasyonların SYİ ne göre, kuraklık oranları \%23 ile \%10 arasında; sulaklık oranlarını ise \%25 ile \%7; normal oranları \%76 ile \%62 arasında değiştiği saptanmıştır.
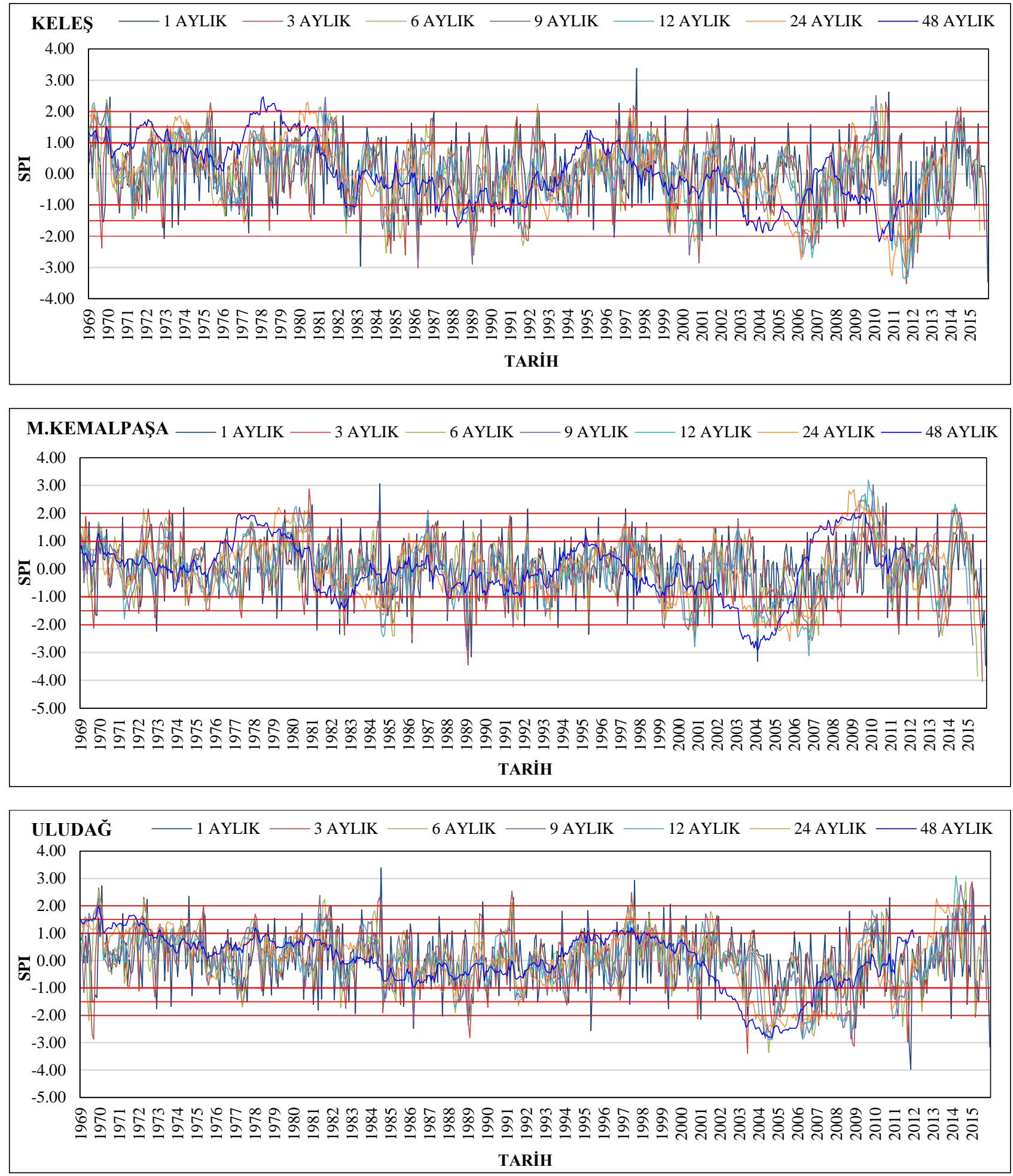

Şekil 4'ün devamı 

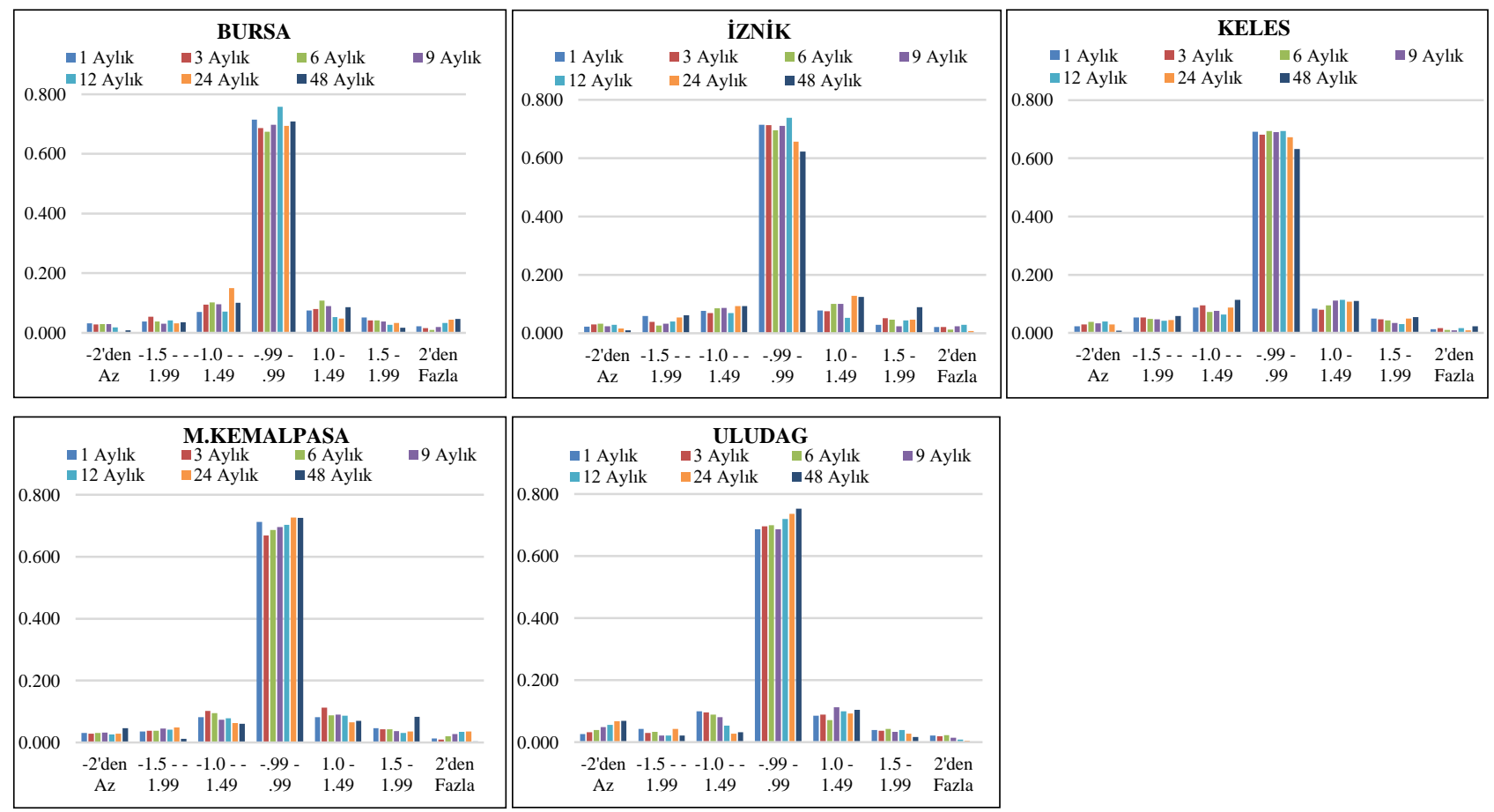

Şekil 5: 1, 3, 6, 9, 12, 24 ve 48 aylık zaman periyotları için SYi değerlerinin frekans grafikleri

\section{Sonuç}

Kuraklık, küresel iklim değişikliği sebebiyle gelecekte daha sık görülmeye başlanacağı öngörülen, canlı yaşamı açısından ciddi sorunlara yol açan doğal bir afettir. Su kaynaklarının hem yağışlı hem de kurak dönemlerde yönetiminin sağlanması gelecekte su krizi gibi kronik kuraklık sorunlarının yaşanma olasılığını düşürecektir.

- Bursa bölgesinde 1969-2015 yıllarında hafif, orta, şiddetli ve çok şiddetli seviyelerde kuraklıklar görülmüştür.

- $1,3,6,9,12,24$ ve 48 aylık analizlerde elde edilen minimum SYİ değerleri sirasıyla -3,45, -3,52, -4,04, -3,39, 2,41, -1,95, -2,14, maksimum SYİ değerleri sirasıyla 2,50, 2,35, 2,88, 2,88, 3,63, 3,26, 3,12 olarak elde edilmiştir.

- Çalışma yılları süresince incelenen istasyonlarda, 1 aylık analiz için 2015 yılının Aralık ayında $-3,45,3$ aylık analiz için 2011 yılının Ağustos ayında -3,52, 6 aylık analiz için 2015 yılının Eylül ayında -4,04, 9 aylık analiz için 2003 yılının Mayıs ayında -3,39, 12 aylık analiz için 2004 yılının Aralık ayında -2,41, 24 aylık analiz için 2008 yılının Şubat ayında -1,95 ve 48 aylık analiz için 2008 yılının Şubat ayında -2,14 değerleri ile en kurak dönemlerini yaşamıştır.

- Araştırma yılları arasında incelenen istasyonlarda, kuraklık açısından genellikle "Normal" seyretmiştir. Ancak çalışma, Bursa bölgesinin kuraklığa eğilimli olduğunu göstermektedir.

- Bursa bölgesinde yağışın büyük bir kısmı kış mevsiminde yağmaktadır. Kış mevsiminde görülen yağış azlığı nedeniyle meteorolojik kuraklığın şiddetinde artış gözlenmiştir.

- Bursa bölgesi meteorolojik kuraklıktan daha sonra görülen tarımsal ve hidrolojik kuraklık tehlikesi ile de karşı karşıya kalabilir.

Bursa bölgesinin muhtemel kuraklık etkilerinin azaltılması için şu öneriler sıralanabilir;

- Tarımsal faaliyetlerde modernizasyona gidilebilir.

- Kuraklık önlem planı oluşturulabilir.

- Bilinçli su kullanımı eğitimi bireylere verilebilir.

- Gri su kullanımı yaygınlaştırılabilir.

- Kaynakların kullanımı düzenlenebilir, kurumsal önlemler alınabilir, koruma, teknolojik yenilikler ve arazi kullanımının değiştirilmesi gibi önlemler alınabilir.

\section{Kaynaklar}

Bacanlı U.G., (2017), Application of Linear Stochastic Models for Drought Forecasting, 3rd International Conference On Engineering and Natural Sciences, ICENS 2017, May 3-7, Budapest, Hungary, ss.590-596.

Bacanlı U.G., Baran T., Dikbas F., (2017), Paylaştırılmış entropi kavramının kuraklık ölçütü olarak kullanılabilirliği, Pamukkale Üniversitesi Mühendislik Bilimleri Dergisi, 23(3), 232-237. 
Bacanlı U.G., Dikbaş F., Baran T., (2011), Meteorological Drought Analysis Case Study, Central Anatolia. Desalination and Water Treatment, 26, 1-10.

Baran T., Bacanlı U.G., Dikbas F., (2017), Drought analysis with SPI index and entropy, European Water., 60, $263-270$.

Bayazıt M., Yeğen Oğuz E.B., (2005), Mühendisler için İstatistik, Birsen Yayınevi, İstanbul, 198ss.

Cancelliere A., DiMauro G., Bonaccorso B., Rossi G., (2007), Drought forecasting using the Standardized Precipitation Index, Water Resources Management, 21(5), 801-819.

Chen S.T., Kuo C.C., Yu P.S., (2009), Historical trends and variability of meteorological droughts in Taiwan/Tendances historiques et variabilité des sécheresses météorologiques à Taiwan, Hydrological Sciences Journal, 54, 430-441.

Fontaine M.M., Steinemann A.C., (2009), Assessing vulnerability to natural hazards, impact-based method and application to drought in Washington state, Natural Hazards Review, 10(1), 11-18.

Gocic M., Trajkovic S., (2014), Spatiotemporal characteristics of drought in Serbia, Journal of Hydrology, 510, 110-123.

Guhathakurta P., Menon P., Inkane PM., Krishnan U., Sable S.T., (2017), Trends and variability of meteorological drought over the districts of India using standardized precipitation index, Journal of Earth System Science, 126:120.

Guttman N.B., (1998), Comparing the Palmer Drought Index and the Standardized Precipitation Index, Journal of American Water Resources Association, 34(1), 113-121.

Guttman N.B., (1999), Accepting the Standardized Precipitation Index: A calculation algorithm, Journal of American Water Resources Association, 35(2), 311-322.

Kallis G., (2008), Droughts, Annual Review of Environment and Resources, 33, 85-118.

Keyantash J., Dracup J., (2002), The quantification of drought: An evaluation of drought indices, Bulletin of the American Meteorological Society, 83(8), 1167-1180.

Labedzki L., (2017), Categorical Forecast of Precipitation Anomaly Using the Standardized Precipitation Index SPI, Water, 9(8), 114.

Liu L., Hong Y., Bednarczyk N.C., Yong B., Shafer A.M., Riley R., Hocker E.J., (2012), Hydro-Climatological Drought Analyses and Projections Using Meteorological and Hydrological Drought Indices: A Case Study in Blue River Basin, Oklahoma, Water Resources Management, 26(1), 2761-2779.

Liu L., Yang H., Hocker J.E., Shafer M.A., Carter L.M., Gourley J.J., Bednarczyk N.C., Yong B., Adhikari P., (2012), Analyzing projected changes and trends of temperature and precipitation in the southern USA from 16 downscaled global climate models, Theoretical and Applied Climatology, 109, 345-360.

Mallya G., Mishra V., Niyogi D., Tripathi S., Govindraju R.S., (2016), Trends and variability of droughts over the Indian monsoon region, Weather and Climate Extremes, 12, 43-68.

McKee T.B., Doesken N.J., Kleist J., (1993), The relationship of drought frequency and duration to time steps, Preprints, 8th Conference on Applied Climatology, January 17-22 Anaheim, California, ss.179-184.

Mckee T.B., Doesken N.J., Kleist J., (1999), Drought monitoring of climate, Geographical Reviews, 38, 55-94.

MGM, (2018), Meteoroloji Genel Müdürlüğ̈̈, https://www.mgm.gov.tr/veridegerlendirme/il-ve-ilceler-istatistik.aspx?m=BURSA, [Erişim 08 Mart 2018].

Mishra A., Singh V., (2011), A review of drought concepts, Journal of Hydrology, 391(1-2), 202-216.

Raziei T., Saghafian B., Paulo A.A., Pereira L.S., Bordi I., (2009), Spatial patterns and temporal variability of drought in western Iran, Water Resources Management, 23(3), 439-455.

Sırdaş S., Șen Z., (2003), Spatio-temporal drought analysis in the Trakya region, Turkey, Hydrological Sciences-Journal-des Sciences Hydrologiques, 48(5), 809-821.

Thom H.C.S., (1958), A note on the Gamma Distribution, Monthly Weather Review, 86(4), 117-122.

Topçu E., Seçkin N., (2013), L-Momentler ve Standart Yağış İndeksi (SPİ) yardımıyla Seyhan Havzası kuraklık analizi, Ç.Ü Fen ve Mühendislik Bilimleri Dergisi, 29(1), 19-28.

Vicente-Serrano S.M., González-Hidalgo J.C., DeLuis M., Raventós J., (2004), Drought patterns in the Mediterranean area: the Valencia region (eastern Spain), Climate Research, 26(1), 5-15.

Wu H., Hayes M.J., Weiss A., Hu Q., (2001), An evaluation of the standardized precipitation index, the China-Z index and the statistical Z-score, International Journal of Climatology, 21(6), 745-758.

Wu H., Hayes M.J., Wilhite D.A., Svoboda M.D., (2005), The effect of the length of record on the standardized precipitation index calculation, International Journal of Climatology, 25(4), 505-520.

Yuan Y., Zhou W., (2008), Influences of the Indian Ocean Dipole on the Asian summer monsoon in the following year, International Journal of Climatology, 28(14), 1849-1859.

Zarch M.A.A., Sivakumar B., Sharma A., (2015), Droughts in a warming climate: A global assessment of Standardized precipitation index (SPI) and Reconnaissance drought index (RDI), Journal of Hydrology, 526, 183-195.

Zhang Q., Xiao M., Singh V.P., Li J., (2012), Regionalization and spatial changing properties of droughts across the Pearl River basin, China, Journal of Hydrology, vol. 472-473, 355-366. 